\title{
Introduction to special issue on morphosyntactic variation within the individual language user
}

\author{
Kristin Melum Eide and Andrew Weir (iD \\ Department of Language and Literature, NTNU Norwegian University of Science and Technology, \\ 7491 Trondheim, Norway \\ Email for correspondence: kristin.eide@ntnu.no and andrew.weir@ntnu.no
}

(Received 30 September 2020; accepted 30 September 2020)

This thematic issue of the Nordic Journal of Linguistics focuses on morphosyntactic variation within the individual language user. The phenomenon of intraspeaker (micro)variation raises questions which arguably go to the heart of linguistic theory, especially in formal/generative perspective. Chomsky famously argued that '[l]inguistic theory is concerned primarily with an ideal speaker-listener, in a completely homogeneous speech community' (Chomsky 1965:3). Significant progress in formal/generative linguistics has been made on the basis of this idealization, but it has always been clear that it is an idealization. A great number of language users are bi- or multidialectal: that is, their linguistic competence encompasses two or more closely related systems which might pretheoretically be seen as 'variants of the same language'. And the great majority of (perhaps all) language users can (consciously or unconsciously) alter their register use depending on context, a choice which can manifest in sociolinguistic variables such as the realization of phonemes and lexical choice, and also - crucially - differing morphosyntactic structures. Chomsky (2000:59) has stated that 'everyone grows up in a multilingual environment' and that ' $[\mathrm{w}]$ hatever the language faculty is it can assume many different states in parallel'. Sociolinguists have of course been concerned with investigating intraspeaker variability at least since the pioneering studies of Labov (e.g. Labov 1969), but such intraspeaker optionality and variation has received somewhat less attention from linguists in the formal or generative tradition. By now, 55 years after 'Aspects', the generative framework has advanced to the extent that more complicated cases of language competence and performance could and should receive more attention and, ideally, a formal description within one and the same model. The papers in this volume aim to provide empirical investigations of the phenomenon, formulate relevant generalizations, and ultimately contribute to our understanding of what such a model should look like.

The Scandinavian countries, and Norway in particular, are especially interesting testing grounds for the investigation of morphosyntactic variation in the individual, 
both because of the wide dialectal diversity in these countries, and because - in Norway in particular - of the high esteem in which dialects are held, and the tendency of speakers to maintain their native dialects and resist switching to a 'standard' variety even in 'high-register' contexts. There is considerable debate concerning whether Norway has a 'standard spoken language' at all, with an entire special issue of Norsk lingvistisk tidsskrift in 2009 being dedicated to the question (see e.g. Jahr \& Mæhlum 2009). Despite this, speakers master one or more written forms of the language which may be quite distinct from their spoken variety; and it has been argued that, even in 'dialect paradise' Norway, a 'standard' variety does exist (see e.g. Mæhlum 2009 and other papers in the special issue of NLT), and that it has been influencing speakers of dialects. All three papers in this special issue draw on the Norwegian language situation and Norwegian data.

The discussion article by Kristin Melum Eide and Tor A. Åfarli, 'Dialects, registers and intraindividual variation: Outside the scope of generative frameworks?', sets the scene for the issue. Drawing mostly on Norwegian data, Eide \& Åfarli exemplify the kinds of phenomena that an adequate generative theory of intraindividual variation must capture. Crucial to the data explored is to what extent there is an interaction between lexical choice (between a dialectal and a 'standard' form) and the choice of varying syntactic structures, e.g. the use of non-canonical V3 structures. The authors chart the history of generative discussion of variation, exploring the question of to what extent generative syntax can or should make reference to the concept of 'dialect'. They discuss various possibilities for accounting for intraspeaker variation within generative frameworks, focusing on the question of whether there is ever 'non-deterministic' variability within one grammar, or whether all morphosyntactic variability is due to the presence of multiple (sub)grammars, as in Roeper (1999) et seq., and whether 'variation' should in some cases be seen as 'contamination' of one grammar by another grammar, that of a sociologically dominant or prominent (E-)language.

'Contamination' or variation might be seen as the result of some underspecification, or relaxing the conditions on which grammar to use in what context. If so, the larger theoretical and empirical debate is whether such variable syntactic patterns can be modelled as switching between different registers/grammars or as underspecified mappings from form to meaning within one grammar. This debate is continued in the paper 'Code-switching alone cannot explain intraspeaker syntactic variability: Evidence from a spoken elicitation experiment', by Björn Lundquist, Maud Westendorp and Bror-Magnus S. Strand. Specifically, the authors address the question whether speakers activate different grammars when they encounter linguistic input from different registers, in this case written standardized language and spoken dialect. Their two elicitation experiments, comprising some 20 variables (phonological, morphological and syntactic) obtained from 26 high school students from Tromsø, suggest that code/register-switching cannot alone explain syntactic optionality, hence underspecification needs to be taken into account.

We stay in Tromsø for Bror-Magnus S. Strand's article, 'Morphological variation and development in a Northern Norwegian role play register', which investigates the curious properties of the language used by Norwegian children in role play. Even though both children and adults in Tromsø exclusively use their local Tromsø dialect in almost all situations, children in Tromsø (and the rest of Norway) are 
known to switch into a variety closely resembling 'standard East Norwegian'/Oslo dialect when they are engaged in role play. Strand reports a longitudinal study of the role-play register of seven Tromsø children, focusing on the morphological realization of pronouns and of verbal and nominal inflection. Strand confirms previous findings that Norwegian children do indeed 'switch' into a variety resembling East Norwegian in role play, and reports on how the morphological realization of the variables he investigates develops over time in the role-play register, becoming more consistently similar to East Norwegian variants - although with interesting differences depending on the specific variable investigated. As well as being an example of register-conditioned grammatical variation already at a young age, the phenomenon arguably shows that a 'standard' variety can still have influence on the linguistic performance and competence of speakers even in 'dialect paradise' Norway.

In no way do we believe the issue of modelling intraspeaker variation within a formal framework to be settled by the papers in this thematic volume. However, we would like to thank the NJL editors, especially Marit Julien, for the invitation to guest-edit this thematic issue and the opportunity to contribute in our small way to the continuation of this discussion. We also thank the editors for their help and very useful suggestions, and their impressive patience with the process. We would also like to express our heartfelt gratitude to our reviewers who contributed their time and expertise, in some cases stepping in on very short notice (as others struggled with Covid-19) and with correspondingly short deadlines. This volume would not exist without your assistance.

Finally, we thank the authors for submitting their papers to this special issue. We hope our readers will enjoy reading these papers as much as we have enjoyed editing them.

\section{References}

Chomsky, Noam. 1965. Aspects of the Theory of Syntax. Cambridge, MA: MIT Press.

Chomsky, Noam. 2000. The Architecture of Language. New Delhi: Oxford University Press.

Jahr, Ernst Håkon \& Brit Mæhlum. 2009. Har vi et "standardtalemål" i Norge? [Do we have a 'standard spoken language' in Norway?]. Norsk lingvistisk tidsskrift 27(1), 3-6.

Labov, William. 1969. Contraction, deletion, and inherent variability of the English copula. Language 45, $715-762$.

Mæhlum, Brit. 2009. Standardtalemål? Naturligvis! En argumentasjon for eksistensen av et norsk standardtalemål [Standard spoken language? Of course! An argument for the existence of a Norwegian spoken standard language]. Norsk lingvistisk tidsskrift 27(1), 7-26.

Roeper, Thomas. 1999. Universal Bilingualism. Bilingualism 2, 169-186.

Cite this article: Eide KM and Weir A (2020). Introduction to special issue on morphosyntactic variation within the individual language user. Nordic Journal of Linguistics 43, 229-231. https://doi.org/10.1017/ S0332586520000189 